Discussion Paper No. 641

\title{
RATIONAL ADDICTION WITH OPTIMAL INVENTORIES: THEORY AND EVIDENCE FROM CIGARETTE PURCHASES IN JAPAN
}

\author{
Junmin Wan
}

The Seventh ISER-Moriguchi Prize (2005)

Awarded Paper

August 2005

The Institute of Social and Economic Research Osaka University

6-1 Mihogaoka, Ibaraki, Osaka 567-0047, Japan 


\title{
Rational Addiction with Optimal Inventories: Theory and Evidence from Cigarette Purchases in Japan*
}

\author{
Junmin Wan $^{\dagger \ddagger}$ \\ The Institute of Social and Economic Research \\ Osaka University
}

August, 2005

(1st: Dec. 2003)

*This paper received the Osaka University Institute of Social and Economic Research Moriguchi Prize on February 9, 2005. (WEB address) http://www.iser.osakau.ac.jp/moriguchi/7/7syo.html

${ }^{\dagger}$ I wish to thank Kazuo Ogawa for providing guidance and advice while I was writing this paper. I also wish to thank Koichi Futagami, Charles Yuji Horioka, Kaoru Hosono, Daiji Kawaguchi, Kazuo Mino, Tsutomu Miyagawa, Fumio Ohtake, Yoshiyasu Ono, Xiangyu $\mathrm{Qu}$, Masaya Sakuragawa, and Wako Watanabe, as well as seminar participants at Osaka University and Gakushuin University, for their valuable advice and comments. This paper was presented at the 2004 Spring Meeting of the Japanese Economic Association, which took place at Meiji Gakuin University on June 12, 2004; moreover, I wish to thank the discussant, Noriko Hashimoto of Kansai University, and the seminar participants for their useful advice. My thanks go also to several anonymous referees for their helpful comments. Finally, I give special thanks to Shinsuke Ikeda of Osaka University and Keunkwan Ryu of Seoul National University for their extremely helpful suggestions. Any remaining errors are my own.

$\ddagger$ Correspondence: Junmin Wan, The Institute of Social and Economic Research, Osaka University, 6-1 Mihogaoka, Ibaraki, Osaka 567-0047, Japan. Tel: +81(6)6879-8568; Fax: +81(6)6878-2766; E-mail: wan@iser.osaka-u.ac.jp 


\begin{abstract}
A model of rational addiction (RA) with optimal inventories is developed and empirically tested using data on purchases in Japan. If a consumer has information regarding a future price increase, then she may hoard addictive goods; in this case, the optimal inventory period increases with the price hike but decreases with the inventory cost. Owing to the creation of such inventories by consumers, the absolute value of the price elasticity of demand is smaller in the case of a price increase than in that of a price decrease, and this difference is especially salient in the short-run. The evidence provided by daily cigarette purchases is consistent with this asymmetric price effect. Monthly cigarette purchase data do not support the RA hypothesis when inventory is ignored, as inventory becomes an omitted variable that correlates with price; however, this hypothesis does find support if inventory is identified in the demand equation.
\end{abstract}

JEL classification: C12; D11; D12; H31

Keywords: rational addiction, tax increase, hoarding, optimal stopping, asymmetric price effect, omitted variable 


\section{Introduction}

The rational addiction (RA) model developed by Becker and Murphy (1988) has been seen as a radical and powerful way of explaining the consumption of addictive goods, such as cigarettes (see Chalouphka, 1991 and Becker et al., 1994). In empirical studies, econometricians often lack consumption data, but they do tend to have information on purchases. However, if purchase data are used for consumption data without considering rational inventory behavior, as is the case in the existing literature, the resulting estimators may be seriously biased due to omitted inventory effects. For example, Gruber and Köszegi (2000, 2001) replicated the analysis of Becker et al. (1994) to report that the effect on cigarette "consumption" of the following year's tax rate was positive, thereby casting doubt on the validity of the RA hypothesis. By examining monthly cigarette sales in California, Keeler et al. (1993) reported that the coefficient on lagged "consumption" was negative and seemingly inconsistent with RA. These results may be due to the omitted variable problem. To test the validity of the RA hypothesis effectively, it is necessary to incorporate the omitted inventory effect into the structural model.

By incorporating optimal inventory creation into the framework of Becker et al. (1994), the objectives of this paper are to develop a testable RA model, based on aggregate purchase data, and to empirically test the model using Japanese daily and monthly cigarette purchase data. In doing so, to examine whether incorporating inventory actually resolves the omitted variable problem, the empirical results with and without the assumption of optimal inventory selection are compared.

In setting up the optimal inventory model of RA, I first characterize optimal behavior as follows. First, I obtain the closed form solution to the optimal inventory period, thereby showing that (i) if the consumer has certain informa- 
tion on a future price increase, she has an incentive to hoard storable addictive goods, and she decides how many periods' worth of goods she should store by solving an optimal stopping problem; and (ii) the optimal inventory period increases with the price hike, and decreases with the inventory cost. Secondly, I find that the effects on consumption of a price decrease and price increase are asymmetric. The absolute value of the price elasticity of demand is smaller in the case of a price increase than in that of a price decrease, and this difference is especially salient in the short-run.

I examine the empirical validity of the RA model in two ways. First, I empirically examine the hypothesis of an asymmetric price effect using a daily cigarette purchase dataset unique to Japan. The results suggest that consumption does not decrease significantly during the inventory period but does once the inventory has been exhausted. This evidence is consistent with the existence of asymmetric price effects.

Second, I examine whether incorporating inventory actually resolves the omitted variable problem by comparing the empirical results with and without the distinction between consumption and purchase. I test the model using monthly cigarette purchases in Japan, where the central government completely controls the price of cigarettes and cigarette prices are exogenous to consumers. Because a new law must be passed before cigarette taxes can be changed, Japanese cigarette consumers have perfect foresight concerning future prices and hoard large amounts just before a tax increase. If the hoarding associated with a price or tax change is not included in the estimation equation but is included in the error term, consistent estimator will not be obtained. I indeed show that the monthly cigarette purchase data do not support the RA hypothesis when inventory is ignored, but do support it when inventory is considered. 


\section{Related literature}

Several theoretical and empirical issues surrounding RA have yet to be resolved. The first concerns whether it is reasonable to assume that addicts are forwardlooking. Elster and Skog (1999) pointed out that the addict paradoxically engages in voluntary self-destruction. In fact, it is very difficult to insist that the addict is either fully rational (forward-looking) or fully irrational. For example, an addict always uses future price information in deciding how to hoard addictive goods in preparation for her future consumption. This behavior is forward-looking, even though it may be self-destructive to some extent.

Second, it is difficult to test empirically the hypothesis of RA, because many estimation issues arise when actual data are used. Gruber and Köszegi (2000, 2001) pointed to a number of problems with Becker et al.'s (1994) formulation, noting that "very few price increases are announced far in advance (as much as one year)' and that 'forward-looking behavior does not imply time inconsistent preference'; they also noted the presence of a 'sizable hoarding effect' and a 'wrong signed coefficient of next year's tax rate.' Keeler et al. (1993) also noted the hoarding effect and a negative coefficient on lagged consumption. Furthermore, Auld and Paul (2004) pointed out that aggregate data tend to yield spurious evidence in favor of the RA hypothesis.

Third, even in the absence of RA, a problem still arises in the estimation of normal demand and supply equations, primarily for two reasons. First, the price becomes endogenous because demand and supply are determined simultaneously. Therefore, it is very difficult to estimate the demand or supply equation using aggregate data. A natural experiment constitutes a good approach for solving this problem. For example, Angrist et al. (2000) used stormy weather as an instrument for price in estimating fish demand. Second, the price may correlate with some unobserved factors in the error term; for example, consumer's 
hoarding under the condition of a price increase. If a retailer or consumer obtains the weather report and hoards fish in anticipation of a price increase caused by bad weather, the possibility exists that unobserved inventory may correlate with stormy weather. ${ }^{1}$

Recently, several papers have analyzed consumer inventory creation. Feenstra and Shapiro (2001) have pointed out that the Consumer Price Index (CPI) cannot be calculated precisely if inventory creation is not considered, and they have tested this conclusion using data on canned tuna. In addition, Hendel and Nevo (2001) have analyzed supermarket sales and consumer inventories, and tested their model using data on soft drinks. Nevertheless, some important points have not been analyzed in detail: 1) the correlation between the inventory in the error term and the price change, 2) the timing of hoarding, 3) a suitable proxy for inventory, 4) addictive goods, and 5) perishable goods. This paper makes an attempt to address these points.

The rest of the paper is organized as follows. Section 2 presents the theoretical framework. Evidence from daily and monthly purchases are presented in Section 3. My conclusions are presented in Section 4.

\section{Theoretical framework}

\subsection{Rational addiction with optimal inventories}

A representative consumer is assumed to consume two types of goods: services, which cannot be stored, and addictive goods, such as cigarettes, which can be stored for a limited time. ${ }^{2}$ The consumer has to choose her optimal consumption, purchases, and inventory in every period to maximize utility. There are

\footnotetext{
${ }^{1}$ In Angrist et al. (2000), moving averages of the three days' wind speeds and wave heights preceding the trading day were measured as the dummy instrument, stormy.

${ }^{2}$ Here, I do not analyze the issues of self-control and time-inconsistent preferences presented by Winston (1980) and Gruber and Köszegi (2001). In addition, I do not analyze the influence of chemical dependency, which was discussed by Cameron (2000).
} 
so many choices that the consumer's problem is very complex. To simplify the problem, I make several assumptions without loss of generality. First, the shopping cost is assumed to be zero; this is reasonable because cigarette vending machines are ubiquitous in Japan. Under this assumption, the consumer has no incentive to store cigarettes if she knows that the price will decrease; in this case, purchases equal consumption. By contrast, she stores cigarettes if she knows that the price will increase; in this case, purchases exceed consumption. Second, the per-unit cost of storage per unit of time is assumed to be $z$. If one unit of cigarettes is stored for period $t$, the present value of the inventory cost is

$$
z \beta^{1}+z \beta^{2}+\ldots+z \beta^{t}=z \sum_{w=1}^{t} \beta^{w}=z\left(\beta-\beta^{t+1}\right) /(1-\beta),
$$

where $\beta$ is the time discount factor. Therefore, the consumer will hoard cigarettes just before a price increase. Third, the price increase is assumed to occur at time 1, while the consumer can purchase cigarettes (consumption from time 1 to time $\tau$ ) at time 0 . The consumer will choose the rates of consumption and purchases, and the inventory period $\tau .^{3}$ I assume that there are no new tax increases or decreases during the period after a tax or price change; in other words, $P_{0}<P_{1}=P_{2}=\ldots P_{t} \ldots=P_{\infty}$.

I also assume that the price is known with perfect foresight. This is the case in Japan, because the central government regulates cigarette prices, and the Diet must enact a new law before any tax increase can be implemented. Seven cigarette tax changes have been enacted during the postwar period. According to the Asahi Shimbun, the dates on which tobacco tax increase proposals passed in the Diet were April12, 1968; October 25, 1975; February 7, 1980; February

\footnotetext{
${ }^{3}$ This problem is somewhat similar to the timing of retirement; see Kingston (2000) and Samwick (1998) for details.
} 
1, 1983; March 8, 1986; October 6, 1998; and March 4, 2003. The respective dates on which these proposals went into effect were May 1, 1968; December 18, 1975; April 22, 1980; May 1, 1983; May 1, 1986; December 1, 1998; and July 1, 2003. The consumer can stockpile cigarettes after the announcement of a tax increase; therefore, the consumer's budget function can be expressed as

$$
\begin{array}{r}
P_{0} \sum_{t=1}^{\tau} C_{t}+\sum_{t=1}^{\tau} C_{t}\left(z \sum_{w=1}^{t} \beta^{w}\right)+\sum_{t=\tau+1}^{\infty} \beta^{t} P_{t} C_{t}+\sum_{t=1}^{\infty} \beta^{t} Y_{t}=A^{0} \\
\beta=1 /(1+r),
\end{array}
$$

where $C_{t}$ is the quantity of cigarettes consumed in period t. $Y_{t}$ is the consumption of the composite commodity in period t. The composite commodity, $Y$, is taken as the numeraire, so the price of cigarettes in period $t$ is denoted by $P_{t}$. The rate of interest is assumed to equal the rate of time preference; thus, the time discount factor $\beta=1 /(1+r) . \quad \tau$ is the inventory period. The budget function can also be written in a more intuitive form as

$$
\sum_{t=1}^{\infty} \beta^{t}\left(Y_{t}+P_{t} C_{t}\right)=A^{0}+\sum_{t=1}^{t=\tau} \beta^{t} C_{t}\left[\left(P_{t}-P_{0} \beta^{-t}\right)-z\left(\beta^{1-t}-\beta\right) /(1-\beta)\right] .
$$

In equation (1), $\sum_{t=1}^{t=\tau} \beta^{t} C_{t}\left(P_{t}-P_{0} \beta^{-t}\right)$ is the present value of the total gain caused by inventory, while $\sum_{t=1}^{t=\tau} z C_{t}\left(\beta-\beta^{t+1}\right) /(1-\beta)$ is the present value of the total inventory cost. Thus, the second part of the right side of equation (1) is the present value of the net gain from inventory.

According to Becker et al. (1994), the consumer is assumed to be infinitely long-lived and to maximize her lifetime utility and income, which are discounted at the rate $r$. This utility has two components: the utility from addictive goods, such as cigarettes, and that from services. The consumer's problem can be 
expressed as

$$
\max _{\left(C_{t}, Y_{t}, \tau\right)} \sum_{t=1}^{\infty} \beta^{t-1} U\left(C_{t}, C_{t-1}, Y_{t}, e_{t}\right) .
$$

s.t. equation (1)

Here, $e_{t}$ reflects the impact of unmeasured life-cycle variables on utility. The initial condition for the consumer in period $1, C^{0}$, measures the level of cigarette consumption in the period before the one under consideration.

The Lagrangian function can be written as

$$
\begin{aligned}
L_{\left\{C_{t}, Y_{t}, \tau\right\}}= & \sum_{t=1}^{\infty} \beta^{t} U\left(C_{t}, C_{t-1}, Y_{t}, e_{t}\right)-\lambda\left\{\sum_{t=1}^{\infty} \beta^{t}\left(Y_{t}+P_{t} C_{t}\right)-A^{0}\right. \\
& \left.-\sum_{t=1}^{t=\tau} \beta^{t} C_{t}\left[\left(P_{t}-P_{0} \beta^{-t}\right)-z\left(\beta^{1-t}-\beta\right) /(1-\beta)\right]\right\} .
\end{aligned}
$$

The associated first-order conditions are ${ }^{4}$

$$
\begin{array}{r}
U_{y}\left(C_{t}, C_{t-1}, Y_{t}, e_{t}\right)=\lambda, \\
U_{1}\left(C_{t}, C_{t-1}, Y_{t}, e_{t}\right)+\beta U_{2}\left(C_{t+1}, C_{t}, Y_{t+1}, e_{t+1}\right) \\
=\lambda\left[P_{0} \beta^{-t}+z\left(\beta^{1-t}-\beta\right) /(1-\beta)\right], \quad \text { for } t \in[1, \tau], \\
=\lambda P_{t}, \quad \text { for } t \in(\tau, \infty], \\
P_{\tau}-P_{0} \beta^{-\tau}=z\left(\beta^{1-\tau}-\beta\right) /(1-\beta) .
\end{array}
$$

${ }^{4}$ This is an optimal stopping problem, and the value-matching and smooth-pasting conditions are implicitly imposed here. The proof in the continuous time framework is presented in Appendix A. 
From equation $(6),{ }^{5}$ I calculate the optimal inventory period:

$$
\tau^{*}=\ln \left[1+\frac{P_{t}-P_{0}}{P_{0}+z \beta /(1-\beta)}\right]^{-1 / \ln \beta}
$$

Cigarettes are perishable and have a best-before date, or time limit. This limit is assumed to be $T^{l}$. Therefore, $\tau=\tau^{*}$ for $T^{l} \geq \tau^{*}$, and $\tau=T^{l}$ for $\tau^{*}>T^{l}$. In consequence, the following proposition obtains.

Proposition 1: If a price or tax increase occurs at time 1 and the price remains constant thereafter, the optimal inventory period increases with the price but decreases with the inventory cost. ${ }^{6}$ The optimal inventory period is also bounded by the time limit $T^{l}, \tau=\tau^{*}$ for $T^{l} \geq \tau^{*}$, and $\tau=T^{l}$ for $\tau^{*}>T^{l}$.

Proof: See the continuous time framework in Appendix A.

Consider a utility function that is quadratic in $Y_{t}, C_{t}$, and $e_{t}$. A linear difference equation can be derived by solving the first-order condition for $Y_{t}$ and substituting it into the first-order condition for $C_{t}$ :

$$
C_{t}=\theta_{0}+\theta C_{t-1}+\beta \theta C_{t+1}+\theta_{1(t)} P_{t}+\theta_{2} e_{t}+\theta_{3} e_{t+1}
$$

\footnotetext{
${ }^{5}$ Here $\tau$ is represented in discrete time, and I approximately differentiate the Lagrangian function with respect to $\tau$. However, it is possible to obtain $\tau$ in a continuous-time framework using the same model, if the optimal inventory period in the discrete-time case converges to one. That is, $\tau^{*}=\ln \left[1+\frac{P_{t}-P_{0}}{P_{0}+z / r}\right]^{1 / r}$ in the continuous-time framework.

${ }^{6}$ The effects of the time discount factor and the interest rate on the optimal inventory period are not uniquely determined.
} 
where,

$$
\begin{aligned}
\theta_{0} & =-\lambda\left(u_{y 1}+\beta u_{y 2}\right), \\
\theta & =\frac{-\left(u_{12} u_{y y}-u_{1 y} u_{2 y}\right)}{\left(u_{11} u_{y y}-u_{1 y}^{2}\right)+\beta\left(u_{22} u_{y y}-u_{2 y}^{2}\right)}, \\
\theta_{1(t)} & =\frac{u_{y y} \lambda\left[P_{0} \beta^{-t} / P_{t}+z\left(\beta^{1-t}-\beta\right) /\left((1-\beta) P_{t}\right)\right]}{\left(u_{11} u_{y y}-u_{1 y}^{2}\right)+\beta\left(u_{22} u_{y y}-u_{2 y}^{2}\right)}, \text { for } t \in[1, \tau], \\
& =\frac{u_{y y} \lambda}{\left(u_{11} u_{y y}-u_{1 y}^{2}\right)+\beta\left(u_{22} u_{y y}-u_{2 y}^{2}\right)}=\theta_{1}, \text { for } t \in(\tau, \infty], \\
\theta_{2} & =\frac{-\left(u_{y y} u_{1 e}-u_{1 y} u_{e y}\right)}{\left(u_{11} u_{y y}-u_{1 y}^{2}\right)+\beta\left(u_{22} u_{y y}-u_{2 y}^{2}\right)}, \\
\theta_{3} & =\frac{-\beta\left(u_{y y} u_{2 e}-u_{2 y} u_{e y}\right)}{\left(u_{11} u_{y y}-u_{1 y}^{2}\right)+\beta\left(u_{22} u_{y y}-u_{2 y}^{2}\right)} .
\end{aligned}
$$

Proposition 2: If a price or tax increase occurs at time 1 and the price remains constant thereafter, the shadow price of the addictive goods during the optimal inventory period increases with time and is lower than the practical price, as a result of consumer inventory creation.

Proof: This result is obvious from $\theta_{1(t)}$ in equation (8).

The consumption good is addictive if $\theta>0$, and the degree of addiction increases with $\theta$. The roots of difference equation (8) are

$$
\phi_{1}=\frac{1-\left(1-4 \theta^{2} \beta\right)^{1 / 2}}{2 \theta}, \phi_{2}=\frac{1+\left(1-4 \theta^{2} \beta\right)^{1 / 2}}{2 \theta}
$$

and the stability conditions are

$$
4 \theta^{2} \beta<1, \phi_{1}<1, \phi_{2}>1 .
$$

Given these roots, the short-run price effect (of a price decrease, no inventory) 


$$
\frac{d C_{t}}{d P^{*}}=\frac{\theta_{1}}{\theta\left(1-\phi_{1}\right) \phi_{2}}
$$

which is defined as the impact of a temporary change in the current and all future prices on current consumption, ${ }^{7}$ with past consumption held constant.

The long-run price effect (of a price decrease, no inventory) is

$$
\frac{d C_{\infty}}{d P}=\frac{\theta_{1}}{\theta\left(1-\phi_{1}\right)\left(\phi_{2}-1\right)},
$$

which is defined as the effect of a permanent change in prices in all periods. ${ }^{8}$

Proposition 3: If the consumer can hoard addictive goods in anticipation of a price increase, but cannot short-sell them prior to a price decrease, the effects of a price decrease and a price increase on consumption following the price changes are asymmetric. The absolute value of the price elasticity of demand is smaller for a price increase than for a price decrease, as a result of consumer inventory creation; this difference is most salient in the short-run.

Proof: This result also is obvious from $\theta_{1(t)}$ in equation (8), under the condition that the consumer cannot consume goods at a lower price in the future.

The essential reason for this asymmetry is market incompleteness. For example, if no futures market exists, then a consumer cannot short-sell cigarettes, even when she knows that the price will fall in the next period.

\footnotetext{
${ }^{7}$ When the price increases, the short-run price effect differs and will be smaller than in the case of a price decrease, because of inventory creation.

${ }^{8}$ When the price increases, the long-run price effect differs and will be smaller than in the case of a price decrease, partly as a result of inventory creation. If $\tau$ is sufficiently small, the long-run price effect of a price increase is similar to that of a price decrease.
} 


\subsection{Issues in empirical analysis}

The consumption set $\left(C_{1}, \ldots, C_{T}\right)$ is decided optimally, but in the context of empirical analysis, $C$ is very difficult to observe. Economists often lack consumption data but have aggregate data on purchases. Nevertheless, purchases do not equal consumption, especially in the short-run. The intertemporal substitution of purchases may offset the intertemporal complementarity of consumption during estimation, if consumption is not distinguished from purchases.

\subsection{Solutions to the issues raised in the empirical model}

The consumption equation is derived in the theoretical model. However, the aggregate quantity consumed is not observable, and only purchase data $Q_{t}$ are available. The relationship between purchases $Q_{t}$ and consumption $C_{t}$ is given by

$$
Q_{t}=I_{t}-I_{t-1}+C_{t}=\Delta I_{t}+C_{t},
$$

where $I_{t}$ denotes inventory at time t. Equation (13) may be rewritten as $C_{t}=$ $Q_{t}-\Delta I_{t}$. Similarly, $C_{t-1}=Q_{t-1}-\Delta I_{t-1}, C_{t+1}=Q_{t+1}-\Delta I_{t+1}$. Then the purchase $Q_{t}$ equation may be used, and purchases substituted for consumption $C_{t}$ in equation (8). Therefore, $Q_{t}$ can be represented in the following form:

$$
\begin{aligned}
Q_{t}= & \theta_{0}+\theta Q_{t-1}+\beta \theta Q_{t+1}+\theta_{1(t)} P_{t}+\theta_{2} e_{t}+\theta_{3} e_{t+1} \\
& +\left(\Delta I_{t}-\theta \Delta I_{t-1}-\beta \theta \Delta I_{t+1}\right) .
\end{aligned}
$$

Note that $\left(\Delta I_{t}-\theta \Delta I_{t-1}-\beta \theta \Delta I_{t+1}\right)$ is the effect of inventory, and that it correlates with the price. Since inventory also correlates with either the tax change or the lead and lag of the price, the error term also correlates with the price change (or tax rate) when $\left(\Delta I_{t}-\theta \Delta I_{t-1}-\beta \theta \Delta I_{t+1}\right)$ is not included on the 
right side of the structural model. Such a typical endogeneity problem is caused by the omission from the model of a variable correlated with the explanatory variable. Moreover, this type of endogeneity bias caused the coefficient of next year's tax rate to be positive in the analysis of Gruber and Köszegi (2000), and the coefficient on lagged consumption to be negative in the study of Keeler et al. (1993).

The optimal inventory and $\Delta I_{t}$ in every period are derived in the theoretical framework. Therefore, I use $\mathrm{T}^{l}$ dummies to indicate $\Delta I_{t}$, one dummy for the hoarding effect, and $T^{l}-1$ dummies for storage effects subsequent to hoarding. According to the theoretical model, the extent of hoarding is a function of tax increases, and the tax increase rate is a good proxy for hoarding. ${ }^{9}$ Therefore, each of the seven tax increases is used to examine the effects of hoarding and storage.

\begin{tabular}{|c|c|c|c|c|c|c|}
\hline Time, & Price $_{t}$, & Hoarding ${ }_{t}$, & ${ }_{t}$, Store $1_{t}$ & Store $2_{t}$ & Store $3_{t} \ldots \ldots . \quad S t$ & Store $T_{t}^{l}$ \\
\hline $\mathrm{t}-2$ & $\mathrm{P}_{1}$ & 0 & 0 & 0 & $\ldots$. & 0 \\
\hline $\mathrm{t}-1$ & $\mathrm{P}_{1}$ & 0 & 0 & 0 & $\ldots$. & 0 \\
\hline $\mathrm{t}$ & $\mathrm{P}_{1}$ & $\left(\mathrm{P}_{2} / \mathrm{P}_{1}\right)$ & 0 & 0 & 0 & 0 \\
\hline $\mathrm{t}+1$ & $\mathrm{P}_{2}$ & 0 & $\left(\mathrm{P}_{2} / \mathrm{P}_{1}\right)$ & 0 & $\ldots \ldots$ & 0 \\
\hline $\mathrm{t}+2$ & $\mathrm{P}_{2}$ & 0 & 0 & $\left(\mathrm{P}_{2} / \mathrm{P}_{1}\right)$ & $\ldots \ldots$ & 0 \\
\hline $\mathrm{t}+3$ & $\mathrm{P}_{2}$ & 0 & 0 & 0 & $\left(\mathrm{P}_{2} / \mathrm{P}_{1}\right) \ldots \ldots$ & 0 \\
\hline$t+4$ & $\mathrm{P}_{2}$ & 0 & 0 & 0 & $\ldots \ldots$. & 0 \\
\hline $\mathrm{t}+\mathrm{T}^{l}$ & $\mathrm{P}_{2}$ & 0 & 0 & 0 & $0 \ldots \ldots\left(\mathrm{P}_{2} /\right.$ & ( $\left.\mathrm{P}_{1}\right)$ \\
\hline $\mathrm{t}+\mathrm{T}^{l}+1$ & $\mathrm{P}_{2}$ & 0 & 0 & 0 & $\ldots \ldots$ & 0 \\
\hline
\end{tabular}

According to 'The History of the Japanese Tobacco Monopoly', the shelf life

\footnotetext{
${ }^{9}$ When the inventory cost $\mathrm{z}$ is sufficiently small and the rate of tax increase is not large, the optimal inventory period $\tau^{*} \approx\left(P_{t}-P_{0}\right) /\left(r P_{0}\right)=$ rate of tax increase $/ \mathrm{r}$.
} 
of cigarettes is about five months, and distribution requires about two months; therefore, the consumer's maximum storage period is about three months. Thus, the purchase equation can be written as

$$
\begin{aligned}
& Q_{t}=\theta_{0}+\theta Q_{t-1}+\beta \theta Q_{t+1}+\theta_{1(t)} P_{t}+\theta_{2} e_{t}+\theta_{3} e_{t+1} \\
& +\left(\Delta \text { Hoarding }_{t}+\Delta \text { Store }_{t}+\Delta \text { Store } 2_{t}+\Delta \text { Store } 3_{t}\right) \\
& -\theta\left(\Delta \text { Hoarding }_{t-1}+\Delta \text { Store }_{t-1}+\Delta \text { Store } 2_{t-1}+\Delta \text { Store } 3_{t-1}\right) \\
& -\beta \theta\left(\Delta \text { Hoarding }_{t+1}+\Delta \text { Store }_{t+1}+\Delta \text { Store } 2_{t+1}+\Delta \text { Store } 3_{t+1}\right) .(15)
\end{aligned}
$$

Since the inventory has the characteristics presented in Figure 1, it can be written as

$$
\begin{aligned}
\Delta \text { Hoarding }_{t} & =-a \Delta \text { Store }_{t+1}, \\
& =-b \Delta \text { Store }_{t+2}, \\
& =-c \Delta \text { Store }_{t+3}, \text { for } 1<a, b, c, .
\end{aligned}
$$

Therefore, the variables on the right side can be written as

$$
\begin{aligned}
& \Delta \text { Hoarding }_{t-1}=-a \Delta \text { Store }_{t}, \\
& \Delta \text { Store }_{t-1}=(b / a) \Delta \text { Store } 2_{t}, \\
& \Delta \text { Store }_{t-1}=(c / b) \Delta \text { Store }_{t} \\
& \Delta \text { Store }_{t+1}=(-1 / a) \Delta \text { Hoarding }_{t}, \\
& \Delta \text { Store }_{t+1}=(a / b) \Delta \text { Store } 1_{t}, \\
& \Delta \text { Store }_{t+1}=(b / c) \Delta \text { Store } 2_{t}, .
\end{aligned}
$$


Then $Q_{t}$ can be written as

$$
\begin{aligned}
Q_{t} & =\theta_{0}+\theta Q_{t-1}+\beta \theta Q_{t+1}+\theta_{1(t)} P_{t}+\theta_{2} e_{t}+\theta_{3} e_{t+1} \\
& +(-\theta) \Delta \text { Hoarding }_{t+1} \\
& +(1+\beta \theta / a) \Delta \text { Hoarding } \\
& +(1+\theta a(1-\beta / b)) \Delta \text { Store }_{t} \\
& +(1-\theta b / a-\beta \theta b / c) \Delta \text { Store } 2_{t} \\
& +(1-\theta c / b) \Delta \text { Store } 3_{t} \\
& +(-\theta) \Delta \text { Store } 3_{t-1} .
\end{aligned}
$$

Before a price increase, purchases exceed consumption; thus, hoarding has a positive effect on purchases. Therefore, $\Delta$ Hoarding $_{t+1}>0$ and $\Delta$ Hoarding $_{t}>$ 0. Moreover, because $0<\theta<1$ and $0<\beta<1,(-\theta) \Delta$ Hoarding $_{t+1}<0$ and $(1+\beta \theta / a) \Delta$ Hoarding $_{t}>0$. After the price increase, because the inventory must have a negative effect on purchases, $\Delta$ Store $1_{t}<0, \Delta$ Store $2_{t}<0$, $\Delta$ Store $3_{t}<0$, and $\Delta$ Store $3_{t-1}<0$. Therefore, $(1+\theta a(1-\beta / b)) \Delta$ Store $1_{t}<0$, $(-\theta) \Delta$ Store $_{t-1}>0$, and the signs of $(1-\theta b / a-\beta \theta) \Delta$ Store $2_{t}$ and $(1-$ $\theta c / b) \Delta$ Store $3_{t}$ are undetermined. ${ }^{10}$ The estimation of purchase equation (16), $Q_{t}$ is discussed in the following section, as data on these variables and suitable proxies for the inventories are available.

\footnotetext{
${ }^{10} \theta_{1(t)}$ is a function of time. When the timing of $\theta_{1(t)}$ is considered, equation (16) can be re-written by using the constant coefficient $\theta_{1}$ and adding another positive term $\theta_{1}\left[-\left(P_{t}-\right.\right.$ $\left.\left.P_{0} \beta^{-t}\right)+z\left(\beta^{1-t}-\beta\right) /(1-\beta)\right]$.
} 


\section{Evidence}

\subsection{Cigarette price and tax in Japan}

The price of cigarettes is totally controlled by the Japanese government, and special laws are passed to enact cigarette tax changes. Seven cigarette tax increases have been passed by the Japanese government, not because of fluctuations in the demand for cigarettes, but because of a large public deficit. ${ }^{11}$ Thus, the price of cigarettes is an exogenous variable for the Japanese consumer. Furthermore, to implement every tax change, a new law must be created. Hence, cigarette tax increases can be considered a natural experiment that can be analyzed in order to examine consumer responses to price changes.

\subsection{Evidence from daily purchases}

\subsubsection{Daily purchases before and after a tax increase}

I now discuss a recent tax change: a new cigarette tax increase law was passed on March 4, 2003, and came into effect on July 1 of the same year. Daily purchase data for cigarettes in Japan, ${ }^{12}$ for the period from April 1 to September 30 are illustrated in Figure 2. The horizontal axis indicates the purchase date, and the vertical axis shows daily purchases. Figure 2 suggests that a big increase in purchases began on June 23, about one week before the price increase, which peaked on June 30, one day before the price increase. This behavior corresponds to the hoarding effect, due to the tax increase, and is consistent with the predictions of the theoretical model of the previous section. After the price increase on July 1, purchases declined. This is the storage effect due to

\footnotetext{
${ }^{11}$ See "The History of the Japanese Tobacco Monopoly" (in Japanese, Niho Tabako Senbaishi).

${ }^{12}$ The daily data were downloaded from The Japan Statistics Bureau by the author in 2003. (http://www.stat.go.jp/data/kakei/200309/zuhyou/a615.xls; http://www.stat.go.jp/data/kakei/200309/zuhyou/a616.xls) The data may no longer be available via download, but they are available from the author upon request.
} 
hoarding and is also consistent with the predictions of the theoretical model.

Table 1 compares purchases before and after the tax hike with average purchases. The average daily purchase per family was 37.43 yen between April 1 and September 30. However, purchases on June 30 were 8.89 times greater than the average daily purchase, and purchases decreased markedly following the tax hike.

\subsubsection{Testing the asymmetric price effect using daily data}

According to the predictions of the theoretical model, consumption should not decrease sharply in the short-run, even when the price increases in practice because of consumer inventory creation. This hypothesis was tested using data on one-year daily purchases that occurred before and after the tax change. In particular, I used Japanese household daily data for the period from April 1, 2003, to March 31, 2004. These data were downloaded from The Japan Statistics Bureau. The results are provided in Table 2.

As mentioned in the previous section, the shelf life of cigarettes is about three months for a consumer; thus, a rational consumer's consumption should not decrease significantly during the inventory period (about three months) following a tax increase. I used data on purchases per three months, both before and after the tax increase, to test whether consumption decreased during this time. From the results of the difference tests provided in Table 2, it is clear that purchases made between April 1 and June 20, 2003, were equal to those made between June 21 and September 31, 2003, while purchases made between January 1 and March 31, 2004, decreased significantly relative to those made between October 1 and December 31, 2003. These results imply that consumption during the inventory period did not decrease; however, consumption did decrease after the hoard of cigarettes had been exhausted. ${ }^{13}$ This is evidence of

\footnotetext{
${ }^{13}$ Possible seasonal effects were omitted. If seasonal effects were taken into account, con-
} 
an asymmetric price effect.

\subsection{Evidence from monthly purchases}

\subsubsection{Data set for an econometric model}

The following data consist of monthly series spanning the period from January 1954 to September $2003 .{ }^{14}$

(Cigarette purchases by Japanese worker households) Purchase $_{t}$ is the monthly total of cigarette purchases, in packs, per capita. The data were taken from the 'Annual Report of Family Income and Expenditure Survey' and were seasonally adjusted using X-12 ARIMA.

(Price) Price $_{t}$ is the real average retail cigarette price per pack in month t. It equals the Tobacco Price Index divided by the CPI. These data were taken from the 'Annual Report on the Consumer Price Index' and the 'Monthly Report on the Retail Price Survey.' Prices were seasonally adjusted using X-12 ARIMA and are measured in 100's of yen, as of 1995, per pack.

(Disposable income) $Y_{t}$ is the real monthly worker household disposable income per capita. These data were taken from the 'Annual Report of Family Income and Expenditure Survey.' This measure equals the total disposable income per family, divided by the total population per family and the CPI. Moreover, these data were seasonally adjusted using X-12 ARIMA, and are measured in 1000's of yen, as of 1995, per capita.

(First difference of disposable income) $\Delta Y_{t}$ is the first difference of monthly disposable income and is measured in 1000's of yen, as of 1995, per capita.

The summary statistics of these variables are presented in Table 4.

sumption would presumably be found to have decreased more sharply, because January is the beginning of the New Year for the Japanese. The New Year vacation is the longest holiday in Japan, and related consumption therefore always increases in the first quarter.

${ }^{14}$ The details are given in Appendix B. 


\subsubsection{Monthly purchase frequency and purchases before and after a tax increase}

Table 3 indicates that the frequency of purchases in June 2003, the month just before the tax increase, increased markedly, while it decreased markedly in July. This observation is consistent with the predictions of the theoretical model.

From Table 3 and Figure 3, it is clear that per family cigarette expenditure increased markedly in June, while it decreased markedly in July 2003. This observation also is consistent with optimal inventory theory.

\subsubsection{Hoard size versus the tax hike}

The amount of hoarding before every tax increase was calculated. According to the prediction of the theoretical model, the amount of hoarding approximately equals the purchase difference between the two months just before the tax increase, if consumption in those two months did not change drastically. The results of these calculations are presented in Table 5. In particular, the amount of hoarding increased with the rate of the tax increase.

$$
\begin{aligned}
\text { tax elasticity of hoarding } & =\frac{\text { (average hoarding)/(average purchase) }}{\text { average rate of tax increase }} \\
& =\frac{1.126 / 1.475}{0.183} \times 100 \% \\
& =418.067 \% .
\end{aligned}
$$

In addition, the estimated tax elasticity of hoarding is astonishingly large. This implies that the consumer should hoard more than four times as much as the average monthly purchase, if the tax rate increases by 100 percent. 


\subsubsection{Unit root tests}

If any variables are non-stationary, problems can arise from statistical inferences using ordinary least-squares (OLS) or two-stage least-squares (2SLS) methods. Therefore, I tested whether each variable was stationary, using the ADF and Phillips-Perron tests. The test results are reported in Table 6 .

Unit root hypotheses for Purchase $_{t}$ with time were rejected at the $1 \%$ significance level. In addition, unit root hypotheses for Price $_{t}$ were rejected at the $5 \%$ significance level. Since unit root hypotheses for $Y_{t}$ could not be rejected at any conventional level of significance, $Y_{t}$ is clearly not stationary. Since unit root hypotheses for $\Delta Y_{t}$ with time were rejected at the $1 \%$ significance level, $\Delta Y_{t}$ may be considered stationary over time.

\subsubsection{Estimation techniques}

OLS and 2SLS were used to obtain the parameter estimates. The OLS estimates may not be consistent because of the endogeneity of past and future consumption (or purchases) and serial correlation among the residuals. Therefore, to ensure consistent estimates, I also used 2SLS.

The 2SLS estimates are consistent and were derived using instrumental variables. ${ }^{15}$ As noted above, the price of cigarettes is an exogenous variable for the Japanese consumer. Furthermore, price strongly correlates with cigarette consumption and, therefore, is a good instrument for cigarette consumption (or purchases). Lagged prices and taxes were used to instrument for past cigarette consumption (or purchases), while the leads of price and taxes were used as instruments for future cigarette consumption (or purchases).

The $\mathrm{Wu}$ test was used to determine whether the OLS estimates were con-

\footnotetext{
${ }^{15}$ To some extent, the estimation procedure used is subject to the critiques of Auld and Grootendorst (2004). But Auld and Grootendorst (2004) also mentioned that instrumentalvariable estimates of the lag and lead of consumption are consistent if prices are exogenous; see pages $1124-25$.
} 
sistent. The over-identification test (OID) was used to test the validity of the overidentifying restrictions.

\subsubsection{Estimation without distinction between purchases and con- sumption}

Equation (8) was estimated, and the resulting estimates are reported in Table

7. Since Purchase $_{t}$, Price $_{t}$, and $\Delta Y_{t}$ are stationary with time, the time trend was included in the estimation equation. In the OLS column, the estimates are inconsistent because of the endogenous explanatory variables. In the 2SLS

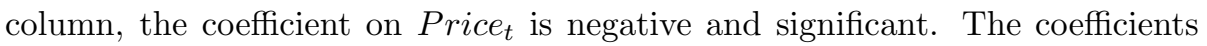
on Purchase $_{t-1}$ and Purchase $_{t+1}$ likewise are negative and significant. In addition, the sign of the estimated coefficients on Purchase $_{t-1}$ and Purchase $_{t+1}$ does not satisfy the addiction condition. These results appear to indicate a durability effect. Therefore, the problem of deriving consistent estimates in this case is similar to that faced by Gruber and Köszegi (2000) and Keeler et al. (1993).

According to the OID test, the set of instruments is invalid in this case. This means that the instruments correlate with the error term, which causes the problem of sign inversion. Therefore, the influence of inventory is serious. If it is ignored, consistent estimates cannot be obtained.

\subsubsection{Estimation with distinction between purchases and consump- tion}

Equation (16) was estimated, and the results are reported in Table 8. Since some of the explanatory variables are stationary with time, the time trend was also included in the estimation equation. The set of instruments used in the 2SLS is valid, according to the OID test. The hypothesis that the OLS estimates are consistent could be rejected at the $5 \%$ level by means of the $\mathrm{Wu}$ test. Therefore, 
the 2SLS estimates are consistent.

In the 2SLS column, the coefficient on Price $_{t}$ is negative and significant. The coefficients on Purchase $_{t-1}$ and Purchase $_{t+1}$ are also negative and significant. Moreover, the sign of the estimated coefficients on Purchase $_{t-1}$ and Purchase $_{t+1}$ now satisfies the addiction condition. The estimated values also satisfy the stability conditions. However, the coefficients on Store $2_{t}$, Store $3_{t}$, and Store $3_{t-1}$ are not significant. ${ }^{16}$ The coefficients on Hoarding ${ }_{t+1}$, Hoarding ${ }_{t}$, and $S t o r e 1_{t}$ are significantly negative, positive, and negative, respectively. ${ }^{17}$

These estimation results, which were derived from data on Japanese monthly cigarette purchases, are consistent with the predictions of the RA model with optimal inventories. I subsequently used the estimated coefficients and sample means provided in Table 4 to estimate the short- and long-run price elasticity given in rows 'short-run $\epsilon$ ' and 'long-run $\epsilon$ ', respectively. The table indicates that the long-run price elasticity is about 2.681 times greater than the short-run value. $^{18}$

\section{Conclusion}

This paper has obtained the following findings. First, I have built a RA model with optimal inventories that provides a theoretical explanation about why the

\footnotetext{
${ }^{16}$ The model incorporates six dummies that indicate tax increases; thus, ordinarily there should have been 42 dummies for the seven times that a tax increase took place. According to theoretical prediction, the optimal inventory period (or quantity) is approximately a linear increasing function of the rate of tax increase. In consequence, to minimize the total number of coefficients estimated, I assumed that inventory was an increasing linear function of the rate of tax increase; thus, it was reasonable that I used only six dummies (corresponding to rates of tax increase) for the seven times that tax increases occurred.

${ }^{17}-\theta \Delta$ Hoarding $_{t+1}$ and $-\theta \Delta$ Store $3_{t-1}$ have the common coefficient $\theta$, but it was expected that the absolute value of $-\theta \Delta$ Hoarding $_{t+1}$ should be much larger than that of $-\theta \Delta$ Store $3_{t-1}$, because the dummy for $\Delta$ Hoarding $t+1$ captures the effect of hoarding, while the dummy for $\Delta$ Store $3_{t-1}$ captures the effect of store changes after hoarding. A comparison of the signs of the two estimated coefficients is also meaningful in this case.

${ }^{18}$ The absolute value of the elasticity is in this case higher than that estimated by Wan (2004), perhaps because the data set differs, or because the effects of health information have not been considered.
} 
estimated coefficient on lagged "consumption" may be negative and the estimated coefficient on the next year's tax rate may be positive. Such results indicate that the consumer uses information on future prices to decide how many storable addictive goods to hoard in preparation for her future consumption. The optimal inventory period increases with the price hike, but decreases with the inventory cost and is also bounded by the shelf life of the goods. Because purchases are not equal to consumption in every period, the intertemporal substitution of purchases generally offsets, and may even exceed, the intertemporal complementarity of consumption that derives from the hypothesis of RA.

Second, the effects of a price decrease and a price increase are asymmetric, and market demand is kinked, owing to inventory creation. In other words, the absolute value of the price elasticity of demand is smaller in the case of a price increase than in that of a price decrease, and this difference is most salient in the short-run. Evidence from a unique data set on daily cigarette purchases in Japan is consistent with asymmetric price effects.

Thirdly, I have empirically examined the RA model using monthly cigarette purchases in Japan, both with and without the distinction between consumption and purchase, since peculiar policies on cigarette price and tax changes provide a suitable context for testing consumer responses to price changes, in terms of purchases and consumption. The estimated coefficients are sign-reversed when consumption is not distinguished from purchases, because inventories become an omitted variable in the error term and correlate with prices and taxes. I have obtained evidence that is consistent with the predictions of a model of RA with optimal inventories; this evidence was obtained through the substitution of purchases for consumption and the inclusion of inventory dummies in the purchase equation.

When the government uses new taxes as a means of regulating the consump- 
tion of harmful, addictive goods, such as cigarettes or heroin, tax effects may be smaller than those anticipated because of consumer inventory creation, especially in the short-run. This important point should be considered in the design of regulations. In addition, the model presented in this paper has other possible applications. For example, inventory effects matter not only in the case of cigarette tax increases, but also in those of changes in the taxes levied on other storable goods. Even in the absence of consumption data, structural consumption equations can be consistently estimated on purchase data if inventories are identified.

In future research, it would be challenging and interesting, following Gruber and Köszegi (2000), to incorporate time inconsistent preferences into the rational addiction model with optimal inventories; this could be accomplished by considering inventory as a self-control device. Another promising topic deserving future investigation involves consumer responses to other factors, such as health information. ${ }^{19}$ In addition, the consumption and inventory of oil may conveniently be analyzed in this framework, as its substitutes are expensive and it may be viewed as an addictive good. These extensions are left for future work.

\section{Appendix A: Continuous time framework}

Consider the model in a continuous-time framework, and then solve the consumer's problem for the optimal inventory period $\tau^{*}$ and the consumption set $\left(C_{t}^{*}, Y_{t}^{*}\right)$. This is a standard optimal stopping problem; thus, the traditional solution approach used here involves the conversion of time to two periods, the post-inventory period $(\tau, \infty]$ and the pre-inventory period $(0, \tau]$. $P_{0}<P_{0^{+}}=P_{t}$ for $t \in(0, \infty]$.

\footnotetext{
${ }^{19}$ These responses have been partially analyzed by Wan (2004).
} 


\section{Post-inventory problem}

Suppose that the consumer makes a consumption plan for the post-inventory period $(\tau, \infty]$ at time 0 . Then, the consumer's problem is given by

$$
\begin{aligned}
\Gamma\left(A^{\tau}, S^{\tau}, \tau\right) & =\max _{\left(Y_{t}, C_{t}\right)} \int_{\tau}^{\infty} e^{-r t} U\left(Y_{t}, C_{t}, S_{t}\right) d t . \\
\text { s.t. } \dot{A}_{t} & =r A_{t}-P_{t} C_{t}-Y_{t}, \\
\dot{S}_{t} & =C_{t}-\sigma S_{t},
\end{aligned}
$$

where the $S$ means the consumption capital of addictive goods and the $\sigma$ means the instantaneous depreciation rate. This setting is the same as Becker and Murphy (1988). The Lagrangian function is

$$
\begin{aligned}
L_{\left\{Y_{t}, C_{t}\right\}}=\int_{\tau}^{\infty}\left[e^{-r t} U\left(Y_{t}, C_{t}, S_{t}\right)\right. & -\lambda_{t}\left(\dot{A}_{t}-r A_{t}+P_{t} C_{t}+Y_{t}\right) \\
& \left.-\mu_{t}\left(\dot{S}_{t}-C_{t}+\sigma S_{t}\right)\right] d t
\end{aligned}
$$

The first-order conditions are

$$
\begin{aligned}
U_{y}\left(Y_{t}, C_{t}, S_{t}\right) & =\lambda_{t} e^{r t}, \\
U_{c}\left(Y_{t}, C_{t}, S_{t}\right) & =P_{t} \lambda_{t} e^{r t}-e^{r t} \mu_{t}, \\
\lambda_{t} & =\lambda_{0} e^{-r t}, \\
\mu_{t} & =\int_{t}^{\infty} e^{-(r+\sigma) w+\sigma t} U_{s}\left(Y_{t}, C_{t}, S_{t}\right) d w,
\end{aligned}
$$

where $\lambda$ and $\mu$ are the Lagrange multipliers for $\mathrm{t} \in(\tau, \infty]$.

If the utility function $\mathrm{U}$ is assumed to be quadratic in $\mathrm{C}, \mathrm{Y}$ and $\mathrm{S}$, the optimal solution (steady states) of C, Y, and S and the dynamics are the same form as those in Becker and Murphy (1988), while all solutions here are dependent on 
the optimal inventory $\tau^{*}$.

\section{Pre-inventory problem}

Next, suppose the consumer makes a consumption plan at time $v \in(0, \tau]$. The consumer's problem is then given by

$$
\begin{aligned}
\Psi\left(A^{v}, S^{v}, v\right) & =\max _{\left(\tau, Y_{t}, C_{t}\right)} \int_{v}^{\tau} e^{-r t} U\left(Y_{t}, C_{t}, S_{t}\right) d t+\Gamma\left(A^{\tau}, S^{\tau}, \tau\right) . \\
\text { s.t. } \dot{A}_{t} & =r A_{t}-e^{r t}\left(P_{0}+z \int_{0}^{t} e^{-r w} d w\right) C_{t}-Y_{t}, \\
\dot{S}_{t} & =C_{t}-\sigma S_{t} .
\end{aligned}
$$

Here, $P_{0}+z \int_{0}^{t} e^{-r w} d w$ is the discounted cost at time 0 for consuming per unit $C_{t}$ at time t, thus $e^{r t}\left(P_{0}+z \int_{0}^{t} e^{-r w} d w\right)$ is the current value of per uint cost at time t. Then the Lagrangian function is

$$
\begin{aligned}
L_{\left\{Y_{t}, C_{t}, \tau\right\}}=\int_{v}^{\tau}\left[e^{-r t} U\left(Y_{t}, C_{t}, S_{t}\right)\right. & -\lambda_{t}^{\prime}\left(\dot{A}_{t}-r A_{t}+e^{r t} P_{0} C_{t}\right. \\
& \left.+e^{r t} C_{t} z \int_{0}^{t} e^{-r w} d w+Y_{t}\right) \\
& \left.-\mu_{t}^{\prime}\left(\dot{S}_{t}-C_{t}+\sigma S_{t}\right)\right] d t \\
& +\Gamma\left(A^{\tau}, S^{\tau}, \tau\right) .
\end{aligned}
$$

The first-order conditions are

$$
\begin{aligned}
U_{y}\left(Y_{t}, C_{t}, S_{t}\right) & =\lambda_{t}^{\prime} e^{r t} \\
U_{c}\left(Y_{t}, C_{t}, S_{t}\right) & =P_{t} \lambda_{t}^{\prime} e^{r t}-e^{r t} \mu_{t}^{\prime}, \\
\lambda_{t}^{\prime} & =\lambda_{0}^{\prime} e^{-r t} \\
\mu_{t}^{\prime} & =\int_{t}^{\infty} e^{-(r+\sigma) w+\sigma t} U_{s}\left(Y_{t}, C_{t}, S_{t}\right) d w
\end{aligned}
$$


and the first order condition with respect to $\tau$ is

$$
\begin{aligned}
&-\lambda_{\tau}^{\prime}\left[-\frac{\dot{\lambda_{\tau}^{\prime}}}{\lambda_{\tau}^{\prime}} A_{\tau}-r\right.\left.A_{\tau}+Y_{\tau}+C_{\tau} P_{0} e^{r \tau}+C_{\tau} z\left(e^{r \tau}-1\right) / r\right]-\mu_{\tau}^{\prime}\left[-\frac{\dot{\mu_{\tau}^{\prime}}}{\mu_{\tau}^{\prime}} S_{\tau}-C_{\tau}+\sigma S_{\tau}\right] \\
&=-\lambda_{\tau}\left[-\frac{\dot{\lambda_{\tau}}}{\lambda_{\tau}} A_{\tau}-r A_{\tau}+Y_{\tau}+C_{\tau} P_{\tau}\right]-\mu_{\tau}\left[-\frac{\dot{\mu_{\tau}}}{\mu_{\tau}} S_{\tau}-C_{\tau}+\sigma S_{\tau}\right] .
\end{aligned}
$$

\section{Value-matching and smooth-pasting conditions}

Set $v=\tau$ and impose the value-matching condition, $\Psi\left(A^{\tau}, S^{\tau}, \tau\right)=\Gamma\left(A^{\tau}, S^{\tau}, \tau\right)$,

and the smooth-pasting conditions, $\Psi\left(A^{\tau}, S^{\tau}, \tau\right)_{A}=\Gamma\left(A^{\tau}, S^{\tau}, \tau\right)_{A}, \mu_{\tau^{-}}^{\prime}=\mu_{\tau^{+}}$. Because the time discount rate is assumed to be equal to the interest rate, the growth rate of $\lambda$ is zero and $\lambda$ equals a constant, for $t \in(0, \infty]$. Hence, the following conditions are obtained.

$$
\begin{aligned}
\tau^{*} & =\ln \left[1+\frac{P_{t}-P_{0}}{P_{0}+z / r}\right]^{1 / r}, \\
U_{y} & =\lambda=\lambda^{\prime}=\Psi_{A}=\Gamma_{A}, \text { for } t \in(0, \infty], \\
U_{c} & =\lambda\left(P_{0} e^{r t}+z\left(e^{r t}-1\right) / r\right)-\mu_{t}^{\prime \prime}, \text { for } t \in(0, \tau], \\
& =\lambda P_{t}-\mu_{t}^{\prime \prime}, \text { for } t \in(\tau, \infty], \\
\mu_{t}^{\prime \prime} & =\int_{t}^{\infty} e^{-(r+\sigma)(w-t)} U_{s} d w, \text { for } t \in(0, \infty] .
\end{aligned}
$$

In addition, because $P_{0}, P_{t}, z$ and $r$ are given, the $\tau^{*}$ can be derived by (A.8). Furthermore, if the utility function is specified, the relation between $\mathrm{Y}$ and $\mathrm{C}$ can be derived by (A.9), (A.10), (A.11) and (A.12), $Y_{t}=f\left(C_{t}, S_{t}\right)$ for $t \in(0, \tau]$ and $Y_{t}=g\left(C_{t}, S_{t}\right)$ for $t \in(\tau, \infty]$. The budget function at time 0 is

$$
\begin{aligned}
& P_{0} \int_{0}^{\tau} C_{t} d t+\int_{0}^{\tau} C_{t}\left(z \int_{0}^{t} e^{-r w} d w\right) d t+\int_{0}^{\tau} e^{-r t} Y_{t} d t \\
& +\int_{\tau}^{\infty} e^{-r t}\left(P_{t} C_{t}+Y_{t}\right) d t=A^{0} .
\end{aligned}
$$


Substituting $C_{t}$ for $Y_{t}$ in (A.13), then the budget function becomes

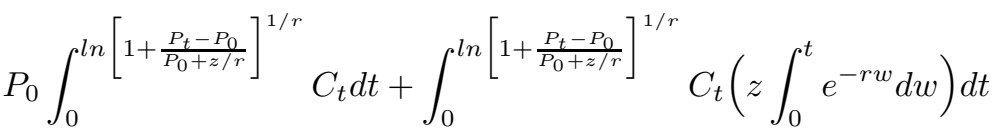

$$
\begin{aligned}
& +\int_{0}^{\ln \left[1+\frac{P_{t}-P_{0}}{P_{0}+z / r}\right]^{1 / r}} e^{-r t} f\left(C_{t}, S_{t}\right) d t
\end{aligned}
$$

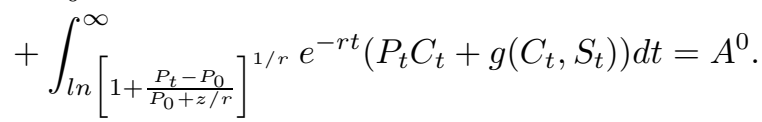

(A.14) is a complicate function of $C_{t}$. By incorporating the (A.3) and (A.6) into

(A.14), if the consumption set $C_{t}^{*}$ can be solved, the $Y_{t}^{*}$ can also be solved. ${ }^{20}$ The consumption set $\left(C_{t}^{*}, Y_{t}^{*}\right)$ for $t \in(0, \infty]$ depend on the optimal inventory period $\tau^{*}$. During the inventory period, the inventory affects consumption by two effects. The first is the income effect caused by the total money saved by inventory. The second is the price effect caused by the inventory cost which changes with time. After the inventories are used up, there are still two effects on the optimal consumption set $\left(C_{t}^{*}, Y_{t}^{*}\right)$, the income effect and the price effect which is caused by the changed consumption capital $S_{t}$. The optimal purchase at time zero is

$$
\int_{0}^{\tau^{*}} C_{t}^{*} d t
$$

and nothing for $t \in\left(0, \tau^{*}\right]$.

\section{Appendix B: Data}

Consumer Price Index, Statistics Bureau Ministry of Public Management, Home Affairs, Posts and Telecommunications, Japan. Annual Report on the Consumer Price Index, 1951-2003.

${ }^{20}$ A.14 is too complicate to obtain a closed form solution of $C_{t}$. 
Consumer Price Index of Cigarettes, Statistics Bureau Ministry of Public Management, Home Affairs, Posts and Telecommunications, Japan. "Subgroup Index for Japan". Annual Report on the Consumer Price Index, 19512003.

Nominal Worker Household Disposable Income, Economic Planning Agency, Government of Japan. Annual Report of Family Income and Expenditure, 1951-2003.

Nominal Retail Cigarette Price, Statistics Bureau Ministry of Public Management, Home Affairs, Posts and Telecommunications, Japan. "Nationwide Uniform Prices or Charges" Monthly Report on the Retail Price Survey, 2003.

Normal Cigarette Price, Nominal Retail Cigarette Price (2003) times consumer price index of cigarettes divided by the index (2003).

Per Capital Worker Household Cigarette Purchases, Per worker household total cigarette consumption expenditure divided by per household population.

Real Household Disposable Income, Nominal Household Disposable Income divided by the consumer price index. 


\section{References}

[1] Angrist, Joshua D., Graddy, Kathryn, and Imbens, Guido W. "The Interpretation of Instrumental Variables Estimators in Simultaneous Equations Models with an Application to the Demand for Fish." Review of Economic Studies 2000, 67(3), 499-527.

[2] Auld, M. Christopher and Grootendorst, Paul. "An empirical analysis of milk addiction." Journal of Health Economics 2004, 23(6), pp.1117-1133.

[3] Becker, Gary S., Grossman, Michael, and Murphy, Kevin M. "An Empirical Analysis of Cigarette Addiction". American Economic Review, June 1994, 84(3), pp.396-418.

[4] Becker, Gary S. and Murphy, Kevin M. "A Theory of Rational Addiction". Journal of Political Economy, August 1988, 96(4), pp.675-700.

[5] Boyer, Marcel. "A Habit Forming Optimal Growth Model". International Economic Review, October 1978, 19(3), pp.585-609.

[6] Cameron, Samuel. "Nicotine addiction and cigarette consumption: a psycho-economic model." Journal of Economic Behavior and Organization, March 2000, 41(3), pp.211-219.

[7] Chaloupka, Frank J. "Rational Addictive Behaviour and Cigarette Smoking". Journal of Political Economy, August 1991, 99(4), pp.722-42.

[8] Elster, Jon and Skog, Ole-Jørgen. Getting Hooked: Rationality and Addiction. Cambridge University Press 1999.

[9] Feenstra, Robert C., and Shapiro, Matthew D. "High-Frequency Substitution and the Measurement of Price Indexes". NBER Working Paper Series, 2001, No.8176. 
[10] Gruber, Jonathan and Köszegi, Botond. "Is Addiction "Rational"? Theory and Evidence." NBER Working Paper No.7507, 2000.

[11] Gruber, Jonathan and Köszegi, Botond. "Is Addiction "Rational"? Theory and Evidence." Quarterly Journal of Economics, November 2001, 116(4), pp.1261-1303.

[12] Hausman, Jerry A. "Specification Tests in Econometrics". Econometrica, November 1978, 46(6), pp.1251-71.

[13] Hendel, Igal, and Nevo, Aviv. "Sales and Consumer Inventory". Institute of Business and Economic Research, Economics Department Working Papers, University of California, Berkeley, 2001.

[14] Horioka, Charles Yuji. "Stimulating Personal Consumption by Taxation." Nihon Keizai Shimbun, 18 January 2002, page 29.

[15] Horioka, Charles Yuji. "To Fix Economy, End Consumption Tax." The Daily Yomiuri, 19 February 2002, page 9.

[16] Japan Tobacco and Salt Corporation. "Tobako Senbaishi" (in English, The History of Japanese Tobacco Monopoly), Vol.1-6, 1963-1990.

[17] Keeler, Theodore E., Hu, Teh-Wei, Barnett, Paul G. and Manning, Willard G. "Taxation, Regulation, and Addiction: A Demand Function for Cigarettes based on Time-series Evidence." Journal of Health Economics, April 1993, 12(1), pp.1-18.

[18] Kingston, Geoffrey H. "Efficient Timing of Retirement." Review of Economic Dynamics, October 2000, 3(4), pp.831-840.

[19] Ryder, Harl E. and Heal, Geoffrey M. "Optimum Growth with Intertemporal Dependent Preference". Review of Economic Studies, January 1973, 40(1), pp.1-31. 
[20] Samwick, Andrew A. "New evidence on pensions, social security, and the timing of retirement." Journal of Public Economics, November 1998, 3(4), pp.207-236.

[21] Statistics Bureau and Statistics Center, Government of Japan. Consumer Price Index, 1951-2003.

[22] Wan, Junmin. "Habit, Information and Uncertainty: Some Evidence from Natural Experiments". December 2004, Doctoral Dissertation, Osaka University.

[23] Wan, Junmin. "Cigarette Tax Revenues and Tobacco Control in Japan." Applied Economics, forthcoming, 2005.

[24] Watanabe, Katsunori; Watanabe, Takayuki and Watanabe, Tsutomu. "Tax policy and consumer spending: evidence from Japanese fiscal experiments." Journal of International Economics, April 2001, 53(2), pp.261-281.

[25] Winston, Gordon C. "Addiction and Backsliding: A Theory of Compulsive Consumption." Journal of Economic Behavior and Organization, December 1980, 1(4), pp.295-384.

[26] Wu, De-Min. "Alternative Tests of Independence Between Stochastic Regressors and Disturbances". Econometrica, July 1973, 41(4), pp.733-50. 
Figure 1 I nventory for tax increase in $t+1$

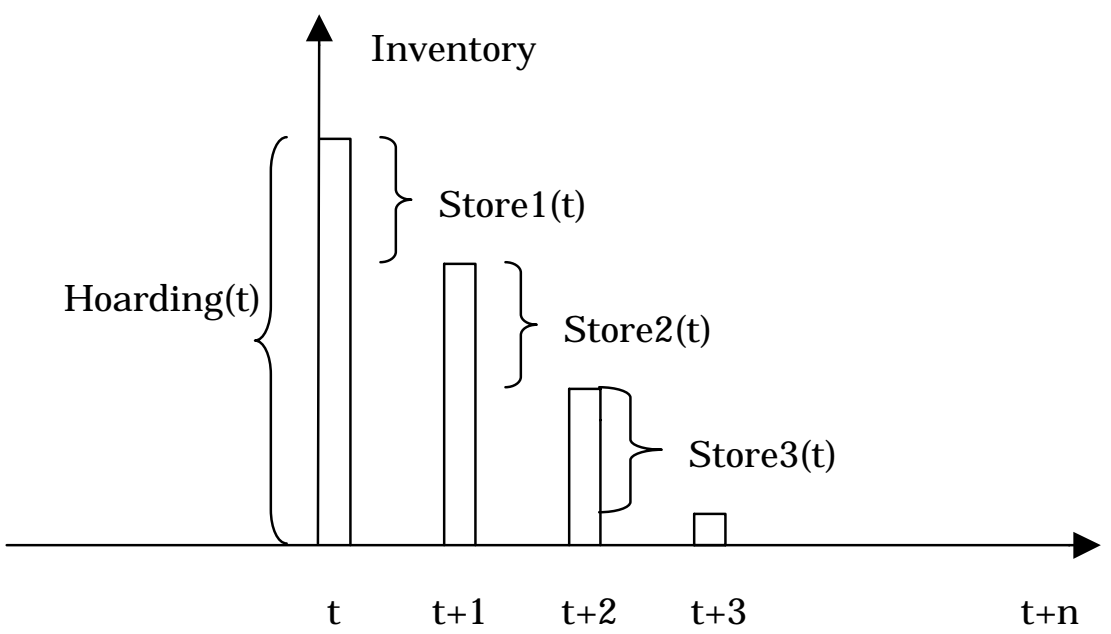

Source: drawn by author 
Figure 2 Daily purchase before and after tax increase

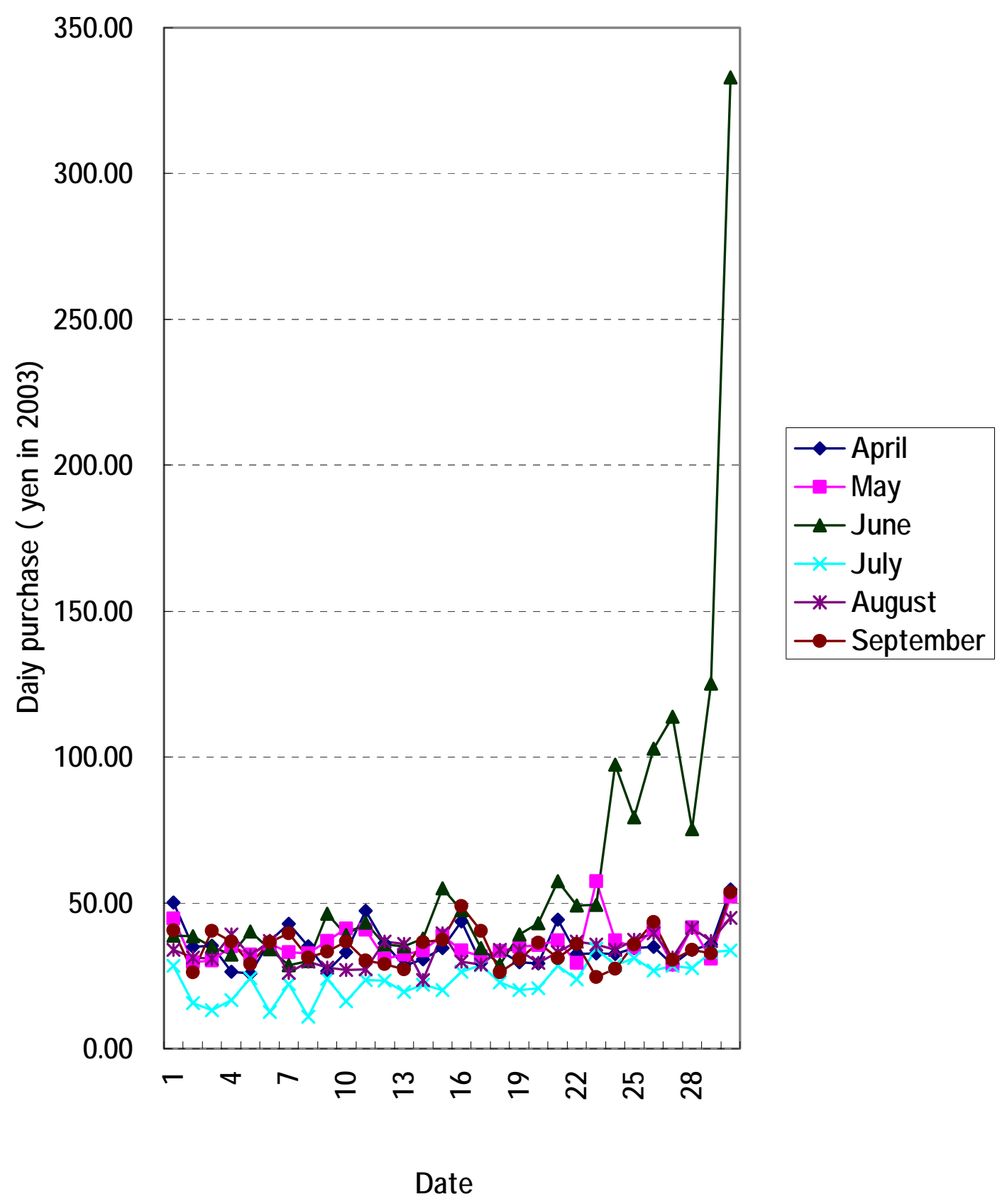

Source: author's calculation based on Report of Family Income and Expenditure 2003 
Figure 3 Monthly cigarette purchase before and after tax increase in 2003

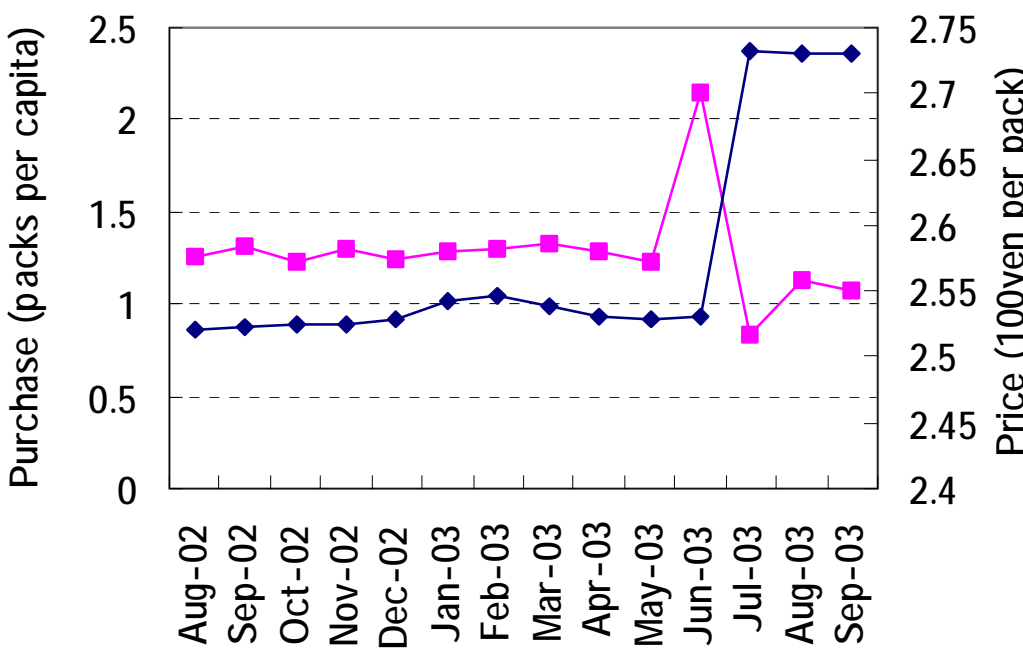

$\rightarrow$ Purchase
(packs per
capita)
$\rightarrow-$ Real price
(100 yen per
pack)

Source: author's calculation based on Annual Report of Family Income and Expenditure, 20022003 
Figure 4 Real and nominal cigarette price J an. 1954 - Sep. 2003

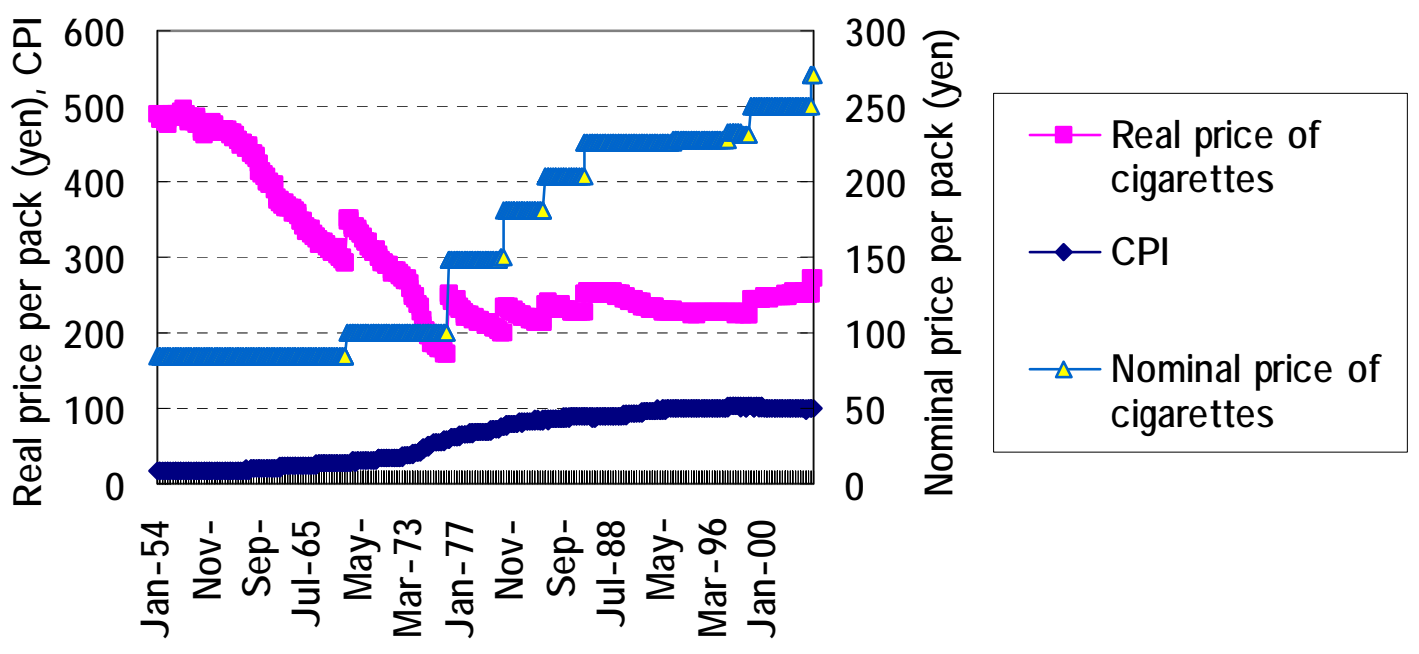

Source: Annual Report on the Consumer Price Index, Monthly Report on the Retail Price Survey 
Figure 5 Per capita cigarette purchase versus rate of tax increase J an. 1954 - Sep. 2003

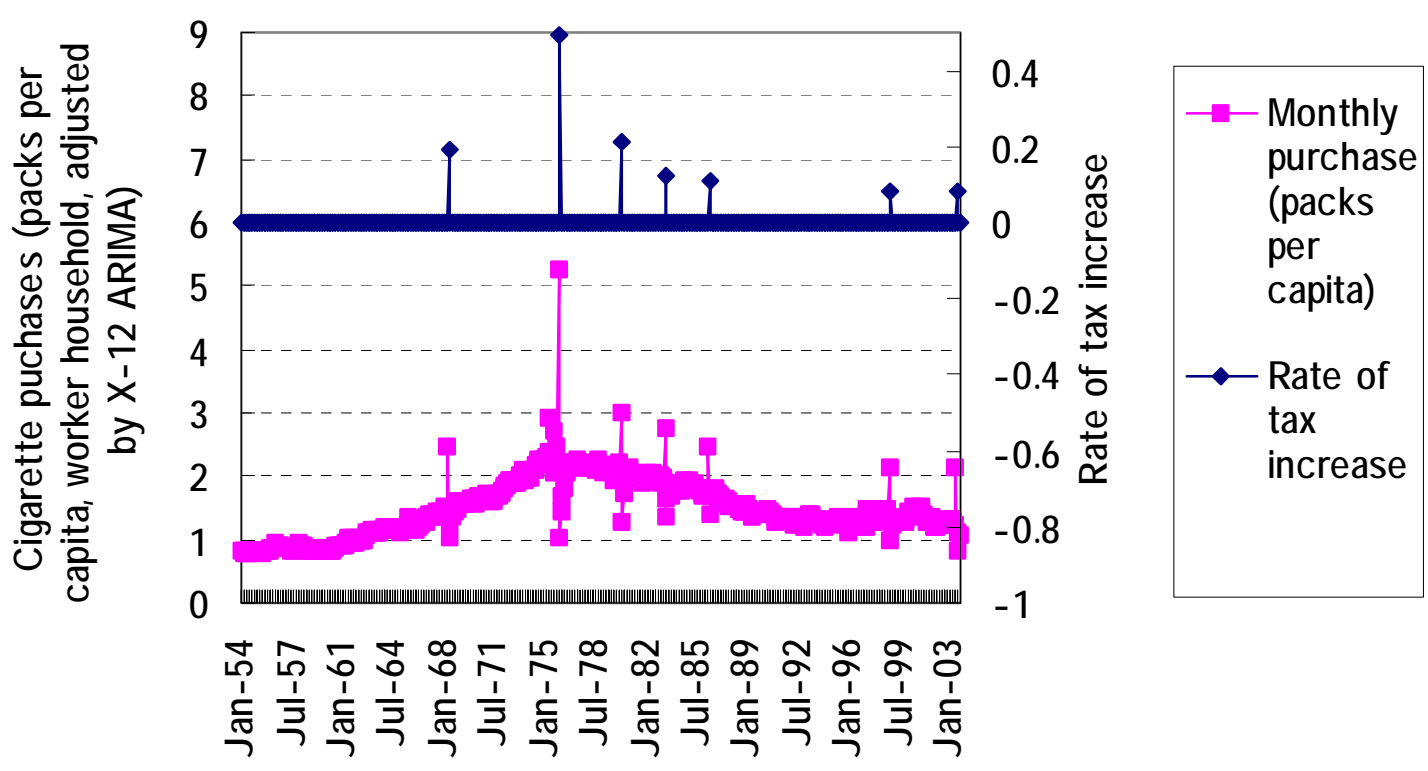

Source: Annual Report of Family Income and Expenditure Survey 
Table 1 Daily purchase before and after tax increase

\begin{tabular}{|c|c|c|c|c|}
\hline & \multicolumn{2}{|c|}{ before tax increase } & \multicolumn{2}{c|}{ after tax increase } \\
\hline & purchase & purchase/ average & purchase & purchase/average \\
\hline 8 days & 49.34 & 1.32 & 10.92 & 0.29 \\
7 days & 97.35 & 2.60 & 22.16 & 0.59 \\
6 days & 79.28 & 2.12 & 12.54 & 0.34 \\
5 days & 102.87 & 2.75 & 24.18 & 0.65 \\
4 days & 113.81 & 3.04 & 16.55 & 0.44 \\
3 days & 75.20 & 2.01 & 13.24 & 0.35 \\
2 days & 125.26 & 3.35 & 15.64 & 0.42 \\
1 day & 332.90 & 8.89 & 28.38 & 0.76 \\
\hline
\end{tabular}

Source: author's calculation based on Report of Family Income and Expenditure 2003 
Table 2 Summary and difference test for the daily purchase before and after the tax increase (from 1 April, 2003 to 31 March, 2004) (tax increase was enforced on $1 \mathrm{~J}$ uly, 2003)

\begin{tabular}{|c|c|c|c|c|c|}
\hline \multicolumn{6}{|c|}{ Summaries } \\
\hline $\begin{array}{r}\text { Variable (pack } \\
\text { capita) }\end{array}$ & period & Obs & Mean & Std. Dev. & Min $\operatorname{Max}$ \\
\hline daily purchase 1 & $\begin{array}{l}\text { from } 1 \text { April to } 20 \text { J une, } \\
2003\end{array}$ & 81 & 0.046 & 0.008 & $0.032 \quad 0.072$ \\
\hline daily purchase 2 & $\begin{array}{l}\text { from } 21 \text { J une to } 31 \text { September, } \\
2003\end{array}$ & 102 & 0.046 & 0.044 & 0.0130 .418 \\
\hline daily purchase 3 & $\begin{array}{l}\text { from } 1 \text { October to } 31 \text { December, } \\
2003\end{array}$ & 92 & 0.040 & 0.008 & $0.024 \quad 0.060$ \\
\hline daily purchase 4 & $\begin{array}{l}\text { from } 1 \text { J anuary to } 31 \text { March, } \\
2004\end{array}$ & 91 & 0.038 & 0.008 & 0.0210 .071 \\
\hline \multicolumn{6}{|c|}{ Difference tests } \\
\hline \multicolumn{3}{|c|}{ Hypothesis } & \multicolumn{2}{|c|}{ t-statistics } & $p$-value \\
\hline \multicolumn{3}{|c|}{$\begin{array}{l}\text { Ho: daily purchase } 1=\text { daily purchase } 2 \\
\text { Ha:daily purchase } 1>\text { daily purchase } 2\end{array}$} & \multicolumn{2}{|c|}{0.008} & 0.497 \\
\hline \multicolumn{2}{|c|}{$\begin{array}{l}\text { Ho: daily purchase } 2=\text { daily purchase } 3 ; \\
\text { Ha:daily purchase } 2>\text { daily purchase } 3\end{array}$} & & \multicolumn{2}{|c|}{1.264} & 0.104 \\
\hline \multicolumn{2}{|c|}{$\begin{array}{l}\text { Ho: daily purchase } 3=\text { daily purchase } 4 \\
\text { Ha:daily purchase } 3>\text { daily purchase } 4\end{array}$} & & \multicolumn{2}{|c|}{1.583} & 0.058 \\
\hline
\end{tabular}

Source: author's calculation based on Report of Family Income and Expenditure 2003-2004 
Table $3 \mathrm{M}$ onthly purchase frequency and expenditure before and after tax increase

\begin{tabular}{c|c|c}
\hline & $\begin{array}{c}\text { Frequency (times per 100 family, } \\
\text { one month) }\end{array}$ & $\begin{array}{c}\text { Expenditure } \\
\text { (yen per family) }\end{array}$ \\
\hline Jan-03 & 99 & 1,098 \\
Feb-03 & 96 & 1,040 \\
Mar-03 & 103 & 1,142 \\
Apr-03 & 101 & 1,107 \\
May-03 & 112 & 1,119 \\
Jun-03 & 110 & 1,884 \\
Jul-03 & 79 & 786 \\
Aug-03 & 99 & 1,089 \\
Sep-03 & 96 & 1,024 \\
\hline \hline
\end{tabular}

Source: author's calculation based on Report of Family Income and Expenditure 2003 
Table 4 Summary statistics: J an. 1954 - Sep. 2003

\begin{tabular}{lcccc}
\hline Variable & Mean & Std.Dev & Max. & Min. \\
\hline Purchase $_{\mathrm{t}}$ & 1.475 & 0.460 & 5.277 & 0.769 \\
Price $_{\mathrm{t}}$ & 2.912 & 0.898 & 4.959 & 1.715 \\
$\mathrm{Y}_{\mathrm{t}}$ & 945.854 & 345.210 & 1439.970 & 273.486 \\
$\Delta \mathrm{Y}_{\mathrm{t}}$ & 1.721 & 26.054 & 108.564 & -134.337 \\
\hline \hline
\end{tabular}

Source: author's calculation 
Table $5 \mathrm{H}$ oarding size versus the rate of tax increase

\begin{tabular}{|c|c|c|c|c|}
\hline $\begin{array}{l}\text { Events of tax } \\
\text { increase }\end{array}$ & $\begin{array}{l}\text { Purchase (2 months } \\
\text { before tax increase) }\end{array}$ & $\begin{array}{c}\text { Purchase (one month } \\
\text { before tax increase }\end{array}$ & Hoarding & $\begin{array}{l}\text { Rate of tax } \\
\text { increase }\end{array}$ \\
\hline 1 & 1.472 & 2.453 & 0.981 & 0.188 \\
\hline 2 & 2.447 & 5.277 & 2.83 & 0.491 \\
\hline 3 & 2.153 & 2.988 & 0.835 & 0.211 \\
\hline 4 & 1.914 & 2.772 & 0.858 & 0.119 \\
\hline 5 & 1.71 & 2.484 & 0.774 & 0.111 \\
\hline 6 & 1.464 & 2.138 & 0.674 & 0.078 \\
\hline 7 & 1.224 & 2.154 & 0.93 & 0.08 \\
\hline Average & 1.769 & 2.895 & 1.126 & 0.183 \\
\hline
\end{tabular}

Source: author's calculation based on Report of Family Income and Expenditure 1954 - 2003 
Table 6 Tests of unit roots (ADF test and Phillips-perron test): Jan. 1954-Sep. 2003

\begin{tabular}{|l|c|c|c|c|c|c|c|c|}
\hline \multirow{2}{*}{ Variable } & \multicolumn{4}{|c|}{ ADF test } & \multicolumn{4}{c|}{ Phillips-pherron test } \\
\cline { 2 - 9 } & constant & time & lag length & test statistics & constant & time & lag length & test statistics \\
\hline Purchase $_{\mathrm{t}}$ & yes & yes & 4 & $-19.236(* * *)$ & yes & yes & 5 & $-6.840(* * *)$ \\
Price $_{\mathrm{t}}$ & no & no & 4 & $-2.363(* *)$ & no & no & 5 & $-2.341(* *)$ \\
$\mathrm{Y}_{\mathrm{t}}$ & yes & yes & 4 & -0.174 & yes & yes & 5 & -2.059 \\
$\Delta \mathrm{Y}_{\mathrm{t}}$ & yes & yes & 4 & $-17.807(* * *)$ & yes & yes & 5 & $-57.206(* * *)$ \\
\hline \hline
\end{tabular}

Note: $* * *$ : significant at $1 \%$ level; $* *$ : significant at $5 \%$ level; $*$ : significant at $10 \%$ level 
Table 7 Estimation results without distinction between purchase and consumption (do not consider optimal inventory)

\begin{tabular}{|c|c|c|c|c|}
\hline \multirow{2}{*}{$\begin{array}{c}\text { Independent } \\
\text { Variable }\end{array}$} & \multicolumn{2}{|c|}{ OLS } & \multicolumn{2}{|c|}{ 2SLS } \\
\hline & Coefficient & t-statistic & Coefficient & t-statistic \\
\hline Constant & $2.467(* * *)$ & 12.738 & $7.587(* * *)$ & 13.731 \\
\hline Purchase $_{t-1}$ & $0.235(* * *)$ & 6.194 & $-0.264(* * *)$ & -3.484 \\
\hline Purchase $_{t+1}$ & $0.177(* * *)$ & 4.394 & $-0.572(* * *)$ & -5.800 \\
\hline Price $_{t}$ & $-0.415(* * *)$ & -12.163 & $-1.268(* * *)$ & -13.542 \\
\hline$\Delta Y_{t}$ & 0.000 & -1.181 & 0.000 & -0.206 \\
\hline Time & $-0.001(* * *)$ & -10.445 & $-0.004(* * *)$ & -12.836 \\
\hline Adjust R-square & 0.787 & & \multicolumn{2}{|c|}{0.539} \\
\hline OID ratio & & & \multicolumn{2}{|c|}{92.508} \\
\hline Wu ratio & & & \multicolumn{2}{|c|}{100.510} \\
\hline Observations & 593 & & \multicolumn{2}{|l|}{593} \\
\hline
\end{tabular}

Note: ***: significant at $1 \%$ level; **: significant at $5 \%$ level; $*$ : significant at $10 \%$ level;

The instruments of 2SLS Column: two lags and two leads of price, hoarding dummy, store dummy and other explanatory variables; The critical $5 \%$ value for Chi-square distribution with 4 degrees of freedom (OID test) is 9.488 . The critical $5 \%$ value for Chi-square distribution with 6 degrees of freedom (Wu test) is 12.592. 
Table 8 Estimation results with distinction between purchase and consumption (consider optimal inventory, rational addiction model with optimal inventory)

\begin{tabular}{|c|c|c|c|c|}
\hline \multirow{2}{*}{$\begin{array}{c}\text { Independent } \\
\text { Variable }\end{array}$} & \multicolumn{2}{|c|}{ OLS } & \multicolumn{2}{|c|}{ 2SLS } \\
\hline & Coefficient & $\mathrm{t}$-statistic & Coefficient & t-statistic \\
\hline Constant & $0.277(* * *)$ & 3.511 & $0.663(*)$ & 1.722 \\
\hline Purchase $_{t-1}$ & $0.469(* * *)$ & 13.609 & $0.492(* * *)$ & 3.898 \\
\hline Purchase $_{t+1}$ & $0.463(* * *)$ & 13.306 & $0.343(* * *)$ & 2.834 \\
\hline Price $_{t}$ & $-0.046(* * *)$ & -3.371 & $-0.110(*)$ & -1.712 \\
\hline$\Delta Y_{t}$ & 0.000 & -0.334 & 0.000 & -0.578 \\
\hline Hoarding $_{t+1}$ & $-2.546(* * *)$ & -10.656 & $-1.841(* *)$ & -2.546 \\
\hline Hoarding $_{t}$ & $7.222(* * *)$ & 43.749 & $6.868(* * *)$ & 17.196 \\
\hline Store $1_{t}$ & $-4.898(* * *)$ & -16.986 & $-5.044(* * *)$ & -5.366 \\
\hline Store_2 ${ }_{t}$ & $0.307(* *)$ & 2.235 & 0.317 & 1.223 \\
\hline Store_3 ${ }_{t}$ & 0.165 & 1.308 & 0.207 & 1.336 \\
\hline Store_ $33_{t-1}$ & 0.056 & 0.449 & 0.099 & 0.755 \\
\hline Time & $0.000(* * *)$ & -2.949 & $0.000(*)$ & -1.685 \\
\hline $4 \theta^{2} \beta<1$ & $(* * *)$ & $(-3.810)$ & $(* * *)$ & $(-1.924)$ \\
\hline$\varphi 1<1$ & $(* * *)$ & $(-5.146)$ & $(* * *)$ & $(-3.047)$ \\
\hline$\varphi 1>1$ & $(* * *)$ & (3.533) & $(*)$ & $(1.351)$ \\
\hline short-run $\varepsilon$ & $-0.414(* * *)$ & $(-4.464)$ & $-0.489(* *)$ & $(-2.147)$ \\
\hline long-run $\varepsilon$ & $-1.325(* * *)$ & $(-8.278)$ & $-1.311(* * *)$ & $(-19.074)$ \\
\hline Adjust R-square & 0.975 & & 0.9 & \\
\hline OID ratio & & & 19.1 & \\
\hline Wu ratio & & & 23.9 & \\
\hline Observations & 593 & & 5 & \\
\hline
\end{tabular}

Note: ***: significant at $1 \%$ level; $* *$ : significant at $5 \%$ level; $*$ : significant at $10 \%$ level; The instruments of 2SLS Column: four lags and one lead of price, seven lags of $\Delta Y$, three leads of hoarding dummy, five lags of store dummy and other explanatory variables; The critical 5\% value for Chi-square distribution with 14 degrees of freedom (OID test) is 23.685. The critical $5 \%$ value for Chi-square distribution with 12 degrees of freedom (Wu test) is 21.026. 